\title{
An unusual complication of colonic interposition for oesophageal replacement
}

\author{
J G HARVEY AND M G W KETTLEWELL \\ Nuffield Department of Surgery, Radcliffe Infirmary, Oxford, UK
}

We report a case of delayed fibrosis of the interposed left colon in a 65-year-old man after an operation for peptic oesophageal stricture and suggest that short-term postoperative ventilation should be used in patients undergoing oesophageal replacement by means of colonic interposition.

\section{Case report}

A 65-year-old man presented with an 18-month history of progressive dysphagia, retrosternal pain, epigastric discomfort, and $19 \mathrm{~kg}$ loss of weight. Investigation showed a $5 \mathrm{~cm}$ benign peptic stricture in the distal third of the oesophagus. The patient was prepared for operation with parenteral nutrition. The abdomen was opened through a midline incision, and a $25 \mathrm{~cm}$ long segment of distal transverse colon and splenic flexure, with a complete marginal arcade, was isolated on a left colic vascular pedicle. A distal cologastric anastomosis was fashioned in two layers. The oesophagus was then exposed through a standard posterolateral right thoracotomy, and a distal oesophagectomy was carried out excising the stricture. The proximal oesophagocolic anastomosis was performed without difficulty just below the level of the aortic arch. Throughout the operation the mesocolic arterial pulsation remained normal with no evidence of venous stasis or congestion of the interposed colon. Four hours after operation the patient suffered an acute hypotensive hypoxic episode. His blood pressure was $70 / 50 \mathrm{mmHg}$, the blood gases were $\mathrm{PO}_{2} 8.13 \mathrm{kPa}, \mathrm{PCO}_{2} 5.76 \mathrm{kPa}$, and he required ventilatory support for 12 hours. His subsequent progress was uneventful, although a gastrografin swallow at five days showed some evidence of mucosal oedema (fig 1). When discharged 14 days later he was eating a normal diet.

One month later he was re-admitted with progressive dysphagia. A gastrografin swallow showed that the interposed colon was narrowed throughout its length (fig 2). Oesophagoscopy confirmed a fibrotic stricture at the proximal anastomosis with acute inflammatory change distally within the colon.

After a period of parenteral nutrition his chest

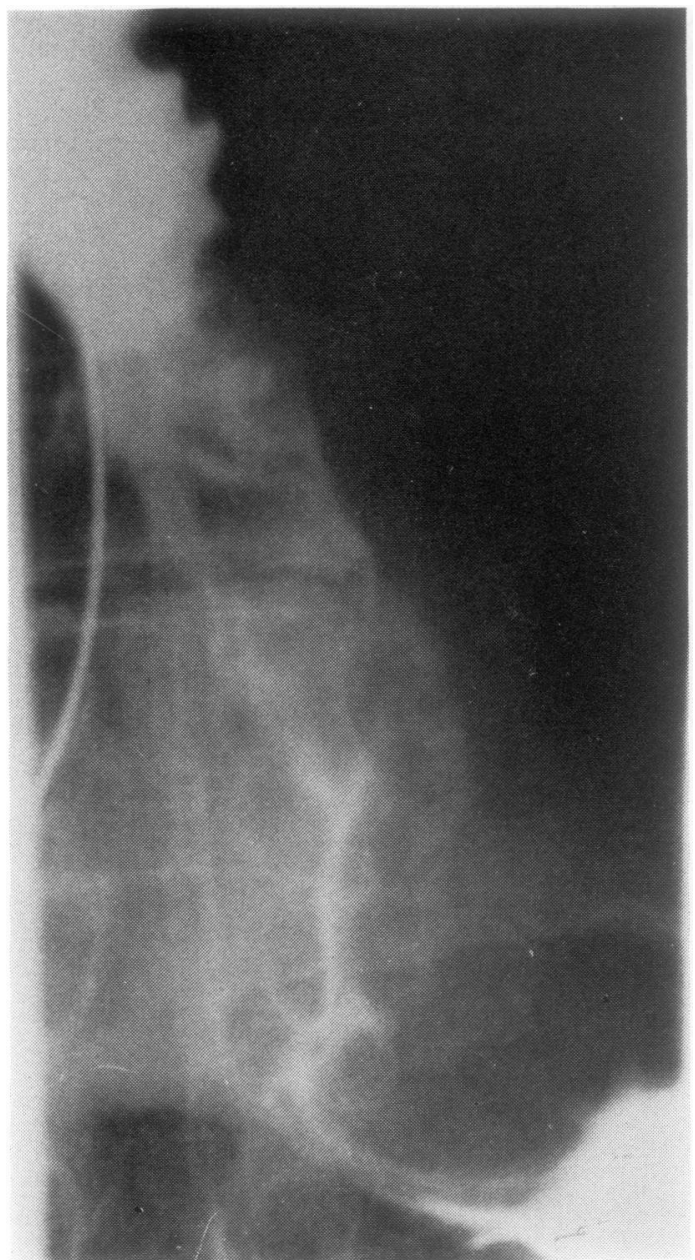

Fig 1 Barium swallow five days after operation showing "thumb printing" of mucosal oedema.

was re-explored. The entire colonic segment had fibrosed but the main vessels of the interposed colon were patent and the artery was pulsating throughout its length. The colonic segment was excised, and an oesophagogastrostomy fashioned. 


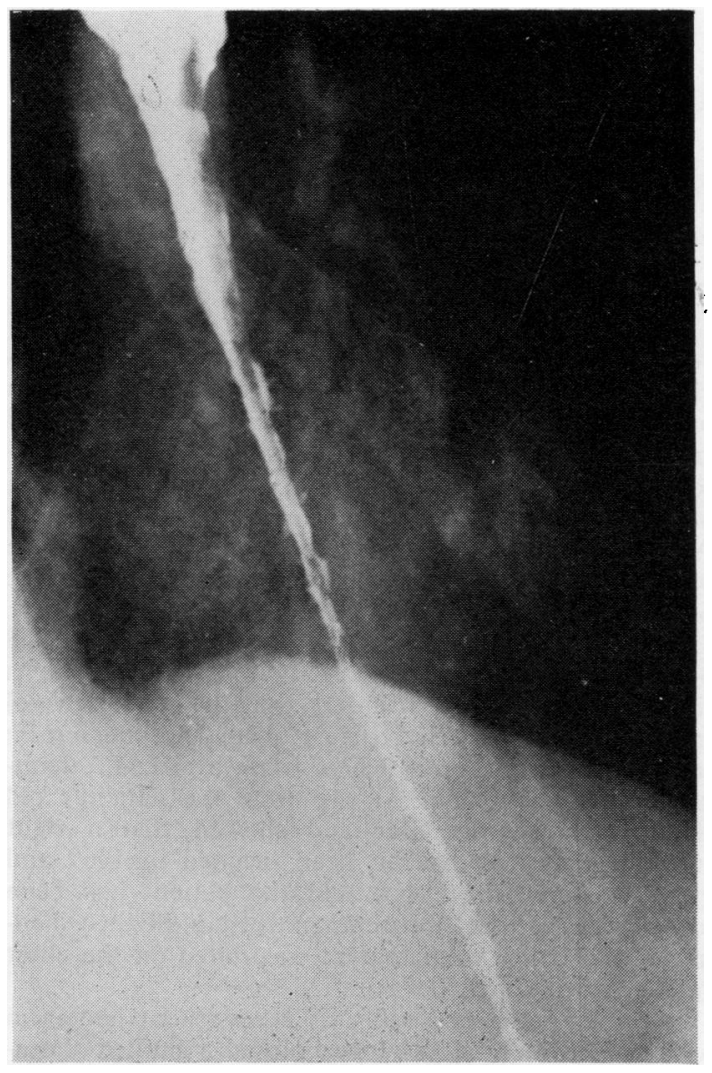

Fig 2 Barium swallow one month after operation showing narrowing of interposed colon.

The patient made an uncomplicated recovery and remains well with no difficulty in swallowing.

\section{Discussion}

The success of colonic interposition depends on the vascular supply. The importance of preoperative angiography, careful handling, and placement of the pedicle have been emphasised by Postlethwaite et al (1971).

The complications of the operation related particularly to the vascular supply of the interposed segment. The incidence of acute necrosis of the colon is reported to be between $5 \%$ and $28 \%$ (Stephens, 1971). We have been able to discover only five published cases of delayed ischaemic stricture of the colon similar to our own case. Four are cited by Hong et al (1964) in a review of 81 colonic interpositions for lye burns of the oesophagus. Hong et al (1964) noted that the interposed segment was often grossly congested after placement and discussed the possibility of progressive intravascular thrombosis.

Linder and Hecker (1962) reported another patient who developed a stricture in the distal half of the interposed segment and speculated that an impaired blood supply might have been the cause.

In our case the development of the stricture was probably related to the acute hypotensive, hypoxic episode that occurred in the early postoperative period. The gastrografin swallow at five days shows some "thumbprinting" of the interposed colon (fig 1) characteristic of ischaemic colitis.

There are few published reports of postoperative management of colonic interposition, but in view of the importance of the vascular supply to the interposed colon stable perfusion pressure and oxygenation must be maintained, particularly in the early postoperative period. We think therefore that there is good reason to use mechanical ventilation for a short period immediately after the operation in all cases of oesophageal replacement using interposed colon.

\section{References}

Hong, P W, Seel, P J, and Dietrick, R B (1964). The use of colon in the surgical treatment of benign stricture of the esophagus. Annals of Surgery, 160, 202-209.

Linder, F, and Hecker, W C (1962). Substitution of the esophagus by colon. Chirurg, 33, 18-23.

Postlethwait, R W, Sealy, W C, Dillon, M L, and Young, W G (1971). Colon interposition for esophageal substitution. Annals of Thoracic Surgery, 12, 89-109.

Stephens, H B (1971). Colon bypass of the esophagus. American Journal of Surgery, 122, 217-222.

Requests for reprints to: J G Harvey, FRCS, Nuffield Department of Surgery, Radcliffe Infirmary, Oxford OX2 6HE. 